Rendon, M. L. (2015). Acciones de adaptación al turismo: la creación de un nuevo espíritu de capitalismo en el Valle del Colca (Arequipa, Perú). Revista Lebret, 7. Bucaramanga, Colombia: Universidad Santo Tomás. pp. 177-204. ISSN: 2145-5996.

\title{
Acciones de adaptación al turismo: la creación de un nuevo espíritu de capitalismo en el Valle del Colca (Arequipa, Perú)*
}

\author{
Actions for adaptation to tourism: the creation of a new spirit of \\ capitalism in the Coca Valley (Arequipa, Peru)
}

María Luisa Rendón Puertas

\begin{abstract}
Resumen
El artículo emplea una perspectiva interdisciplinaria para analizar la creación de un nuevo espíritu del capitalismo. Esto se evidencia a través del análisis de documentos institucionales, la contextualización histórica y la caracterización de dinámicas de adaptación de los actores, en el marco de políticas nacionales, programas y proyectos de desarrollo turístico. Los hallazgos a nivel exploratorio señalan respuestas de los actores y las lógicas a las que corresponden sus acciones, tomando en cuenta lo ocurrido en el Valle del Colca (Arequipa, Perú) en torno al turismo y sus deseos de ingresar al mercado, diversificar sus economías así como participar en proyectos de desarrollo.
\end{abstract}

Palabras clave

Capitalismo, desarrollo, turismo, Arequipa, Perú.

\section{Códigos de clasificación JEL: L83, 021}

\begin{abstract}
The article uses an interdisciplinary perspective to analyze the creation of a new spirit of capitalism. This is put in evidence trough institutional documents analysis, historic contextualization and the characterization of the adaptive dynamics of actors, under the frame of national policies, programs and projects for tourism development. The main findings, at the exploratory level, show the responses of the actors and the logics to which their actions correspond, taking into account what happened in Colca Valley (Arequipa, Peru) around tourism and their desires of entering in the market, diversify their economies as well as to participate in development projects.
\end{abstract}

\section{Keywords}

Capitalism, development, tourism, Arequipa, Peru.

* El artículo deriva del proyecto de investigación: "Políticas públicas en turismo: acción para el desarrollo sostenible en comunidades indígenas y campesinas de Ecuador, Perú y Chile".

1 Doctorado (C) en Ciencias Sociales con especialización en Estudios Andinos. Adscrita a la Facultad Latinoamericana de Ciencias Sociales, FLACSO-Sede Ecuador. Correo electrónico: malurendon@yahoo.com 


\section{Introducción}

El Perú ha seguido un proceso de activación económica y crecimiento impulsado por exportaciones mineras y agroindustriales, el turismo y el incremento en los niveles de consumo interno. No obstante, persisten la exclusión y una serie de problemáticas asociadas con el centralismo y a dinámicas que afectan a las poblaciones rurales.

En los espacios andinos es donde se concentran las explotaciones mineras, la producción agrícola y una serie de actividades de subsistencia. Actualmente, como parte de las políticas del Estado y las intervenciones de cooperación de fundaciones y organizaciones no gubernamentales (ONG) se ha propuesto al turismo como estrategia para alcanzar el desarrollo, generar empleo, diversificar la renta y mejorar las condiciones de vida locales.

A nivel rural los emprendimientos comunitarios de turismo presentan heterogeneidades y conflictos (Prieto, 2011). No todos los actores son homogéneos y las nuevas actividades económicas generan cambios y diferenciaciones dentro de la vida cotidiana y las estructuras de organización.

El caso de estudio se sitúa en el Valle del Colca, en la provincia de Caylloma, en Arequipa. Forma parte de los destinos turísticos del sur de los Andes Peruanos (figura 1). Presenta alturas entre 3200 y 3800 m.s.n.m. y se constituye en un entorno rural con poca "(...) inversión externa significativa o sin alteración del ambiente" (Bidwel, 2011). En el 2014 ha recibido 135000 turistas nacionales y extranjeros y se prevé que la cifra llegue a los 200000 a fines del 2015 (El Comercio, 2015).

Presenta niveles bajos en el índice de desarrollo humano y altos niveles de pobreza (PNUD, 2009). Sus pobladores son campesinos e indígenas, quienes están organizados en unidades productivas familiares (Kervin, 1987; Monge, 1994) y han pasado por procesos migratorios, así como modificaciones en sus estructuras de organización interna y contacto con lo global.

En este valle han surgido acciones que corresponden a intereses por alcanzar el desarrollo y adaptaciones para el turismo. Destacan Chivay, Sibayo, Yanque, Cabanaconde y, en menor grado, Tapay. En él confluyen diversos actores interesados en la actividad turística (tabla 3), entre ellos, pobladores de comunidades, asociaciones, emprendedores de diversa escala, familias (Bidwell, 2011), funcionarios de gobierno y representantes de ONG.

El turismo genera diversas expectativas, pues se le considera como medio para la generación de ingresos y empleo. Contribuye con la puesta en valor de elementos culturales y al mantenimiento de espacios de uso público compartido, así como la conservación de áreas naturales (Gelles, 2000). A nivel local existen acciones de participación, emprendedurismo e intereses para promover el turismo (Rendón y Bidwell, 2015), no obstante, sus efectos e impactos no son todos positivos. 
El turismo configura un campo de conflicto al elevar los precios de la tierra, concentrar o diversificar escasamente la renta, producir diferenciación social, reestructuraciones y cambios de roles en labores femeninas y masculinas (Gascón, 2005), produce contaminación, acceso inequitativo a servicios públicos y recursos locales, banalización en las expresiones culturales y en la producción de artesanías, entre otros múltiples aspectos. Se relaciona con problemáticas amplias, tales como fenómenos migratorios y centralismo. Las estratificaciones que fomenta se acrecientan ante la estructura de un Estado nacional excluyente.

Para analizar esta situación se propone seguir los marcos teóricos en torno a la formación de un nuevo espíritu del capitalismo (Boltanski y Chiapello, 1999) así como las justificaciones en torno a la pluralidad de la acción en el contexto económico (Boltanski y Thévenot, 1996). Estos apuntan a un enfoque de la regulación de la acción colectiva, e intentan amalgamar conceptos de economía y sociología para interpretar la pluralidad de las acciones, al mismo tiempo que las relacionan a diferentes etapas del capitalismo.

Dado que el turismo es una actividad económica afín a los principios del capitalismo, el análisis propuesto intenta responder los siguientes interrogantes: ¿Cuáles son las acciones de adaptación que se presentan en el turismo en el Valle del Colca? y ¿existen principios y acciones que ponen en evidencia la formación de un nuevo espíritu del capitalismo, en el caso de estudio y dentro del contexto nacional?

La respuesta preliminar sugiere que, en el Valle del Colca han surgido adaptaciones para el turismo, las cuales forman parte de los modos de acción de los pobladores locales (Rendón, 2012), quienes tienen intención de participar en proyectos, responder a políticas nacionales para alcanzar el desarrollo y desean tener mejor acceso al mercado (Hill, 2007). Para ello, adoptan prácticas de consumo y producción afines al capitalismo, realizan actividades productivas y de comercialización en los términos del mercado y se intentan posicionar en el contexto de la implementación de proyectos, a nivel local, lo que sugiere la formación de un nuevo espíritu del capitalismo, según lo propuesto por Boltanski, Chiapello y Thévenot, respectivamente (tabla 1).

Tabla 1. Las ciudades como categoría de análisis aplicada al turismo

\begin{tabular}{|c|c|c|c|}
\hline CIUDAD & $\begin{array}{c}\text { PRINCIPIOS SUPERIORES } \\
\text { COMUNES }\end{array}$ & PRUEBA & APLICACIÓN AL TURISMO \\
\hline Inspirada & $\begin{array}{c}\text { Creatividad, inspiración, } \\
\text { sentido artístico, autenticidad }\end{array}$ & $\begin{array}{c}\text { Alguna forma privilegiada } \\
\text { de expresión (ej.: creación de } \\
\text { una obra) }\end{array}$ & $\begin{array}{c}\text { Segundo espíritu del capitalismo, } \\
\text { 1980. Antropología del turismo } \\
\text { (identidad, autenticidad). } \\
\text { Sociología del turismo (estudio } \\
\text { del turista, motivaciones). } \\
\text { Tercer espíritu del capitalismo, } \\
\text { desde 1990 (calidad, } \\
\text { personalización de servicios). }\end{array}$ \\
\hline Doméstica & $\begin{array}{c}\text { Subordinación Posición de } \\
\text { jerarquía } \\
\text { Respeto, fidelidad }\end{array}$ & $\begin{array}{c}\text { Reuniones mundanas } \\
\text { Paternalismo } \\
\text { Protección y sostenimiento }\end{array}$ & $\begin{array}{c}\text { Primer espíritu del capitalismo, } \\
\text { década de 1930 }\end{array}$ \\
\hline
\end{tabular}




\begin{tabular}{|c|c|c|c|}
\hline $\begin{array}{l}\text { De la } \\
\text { Opinión } \\
\text { (del } \\
\text { Renombre) }\end{array}$ & $\begin{array}{l}\text { Renombre } \\
\text { Acumulación de reputación }\end{array}$ & $\begin{array}{c}\text { Presentación pública } \\
\text { Opinión de los otros (número } \\
\text { de personas que acuerdan el } \\
\text { crédito y la estima) }\end{array}$ & $\begin{array}{c}\text { Primer espíritu del capitalismo, } \\
\text { principios s. XX. Turismo de } \\
\text { élite, viajes en tren. } \\
\text { Tercer espíritu del capitalismo, } \\
\text { desde las décadas } 1990 \text { y } 2010 . \\
\text { Turismo alternativo, solidario, } \\
\text { responsable, sostenible, rural- } \\
\text { comunitario. }\end{array}$ \\
\hline Cívica & $\begin{array}{l}\text { Representación } \\
\text { (por voluntad general) }\end{array}$ & $\begin{array}{l}\text { Elecciones } \\
\text { Democracia }\end{array}$ & $\begin{array}{c}\text { Segundo espíritu del capitalismo, } \\
1950-1960\end{array}$ \\
\hline Mercantil & $\begin{array}{l}\text { Enriquecimiento } \\
\text { Acumulación }\end{array}$ & Conclusión de un negocio & $\begin{array}{c}\text { Primer espíritu del capitalismo, } \\
\text { década de } 1930 \\
\text { Segundo espíritu del capitalismo, } \\
\text { décadas de } 1950 \text { - } 1960 \text {, turismo } \\
\text { de masas }\end{array}$ \\
\hline Industrial & $\begin{array}{c}\text { Eficacia técnica } \\
\text { Capacidades profesionales }\end{array}$ & $\begin{array}{c}\text { Prueba técnica } \\
\text { Escala de capacidades }\end{array}$ & $\begin{array}{c}\text { Segundo espíritu del capitalismo. } \\
\text { Décadas } 1960 \text { a } 1980 \text {. Expansión } \\
\text { de la aviación comercial, turismo } \\
\text { de sol y playa }\end{array}$ \\
\hline $\begin{array}{l}\text { De los } \\
\text { Proyectos }\end{array}$ & Desarrollo de la actividad & $\begin{array}{l}\text { Formulación e impulso de } \\
\text { proyectos }\end{array}$ & $\begin{array}{l}\text { Tercer espíritu del capitalismo, } \\
\text { desde 1990. Desarrollo y } \\
\text { cooperación en turismo, } \\
\text { incorporación de la OMT al } \\
\text { Sistema de Naciones Unidas. }\end{array}$ \\
\hline
\end{tabular}

Fuente: Adaptado de: Boltanski y Chiapello, p. 221. Elaboración propia.

Las políticas públicas para el impulso del turismo en el Perú están alineadas a imaginarios globales y a agendas internacionales que hacen un llamado al desarrollo (Rendón, 2015). Los actores, al negociar y adaptarse, generan iniciativas que evidencian diversos modos de acción y permiten abordar las relaciones de poder diferenciadas en las que se enmarcan. Muestran que no solo se orientan a alcanzar beneficios económicos, respondiendo a supuestos capitalistas, sino a garantizar la subsistencia familiar, a mejorar condiciones de vida, a sus deseos de adaptarse al mercado, colaborar hacia objetivos comunes y participar en procesos de desarrollo.

El comprometerse y actuar coordinadamente con otros actores (ONG, cooperación, Estado) con la finalidad de atraer mayores recursos para invertir en obras de infraestructura (Cameron, 2009) así como hacer escuchar sus demandas responde a sus intereses de acumular capital para negociar su posición social, política y económica. Las experiencias encontradas en el Valle del Colca ponen en evidencia la diversidad de actores y sus lógicas de acción y presentan posibilidades para identificar aspectos característicos en torno al turismo, como fenómeno social y como un espacio para la disputa (Prieto, 2011).

Los distritos de Cabanconde y Tapay se encuentran en zonas del cañón donde se realizan actividades de turismo rural y de aventura. Sus poblaciones pertenecen a la etnia cabana, son quechua hablantes y la agricultura constituye su principal ocupación (Rendón, 2012). Ambas localidades han pasado por dinámicas migratorias hacia Arequipa y Lima y al extranjero, principalmente a Estados Unidos (Gelles, 
2000 y Paerregaard, 1997) y sus pobladores han mantenido vínculos con familiares y comunitarios. Esto, a la vez, ha influenciado la economía, sociedad y cultura locales, aportando en adaptaciones en torno al turismo.

Figura 1. Camino hacia el Valle del Colca, por la Reserva Nacional de Salinas y Aguada Blanca (Arequipa, Perú).

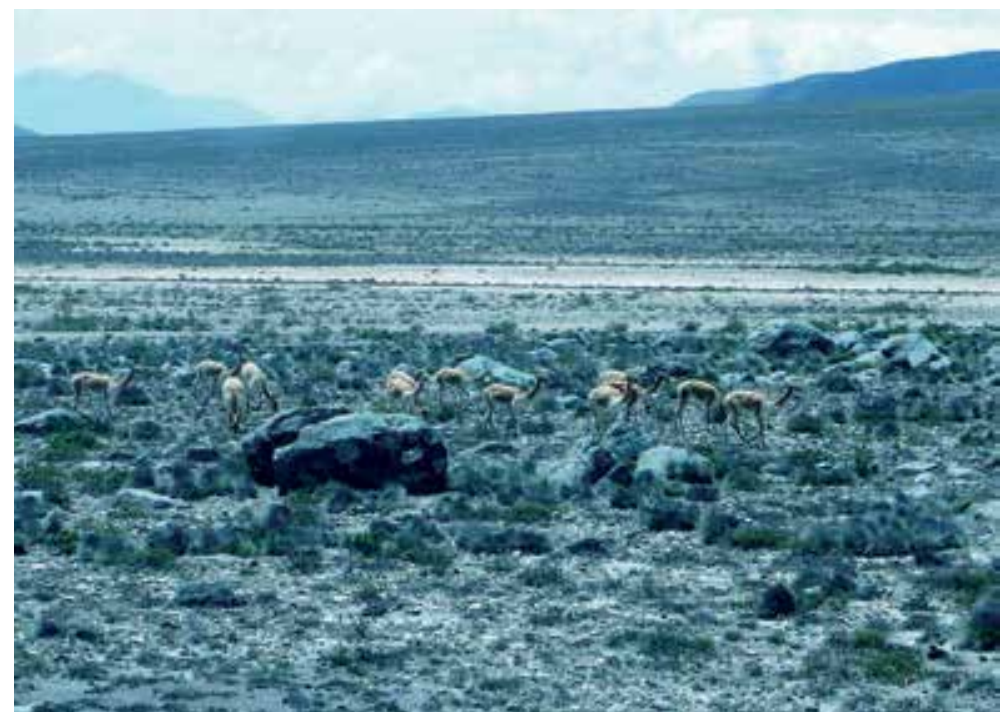

Fuente: la autora

\section{Acercamiento teórico-metodológico para el análisis del caso}

En el Valle del Colca existen conflictos económicos, elementos históricos relacionados con el devenir nacional así como una serie de problemáticas locales propias de las estructuras de organización local. En las últimas décadas se han producido cambios en las condiciones de trabajo y flujos migratorios (Paerregaard, 1997). El turismo ha surgido en respuesta al contexto político y económico, vinculado a dinámicas del desarrollo ya que, de un lado, ha sido promovido por ONG de cooperación como alternativa para reducir la pobreza y, de otro, ha despertado el interés en actores locales que, viendo su potencial para atraer flujos de visitantes y de vender sus productos, han impulsado emprendimientos locales. Se han dado procesos de acumulación y expropiación de tierras así como elevación en el precio de los terrenos y especulación.

Las acciones en torno al turismo llevan a la reconsideración de las funciones de esta actividad como un recurso (Hiernaux-Nicolas, 2002), el cual se convierte en una de las formas de mostrar cómo se insertan los actores en el marco de los procesos 
económicos e históricos nacionales. La integración de las economías locales al mercado global, se da a través de la diversificación de las actividades locales y de la adaptación de las poblaciones al turismo. El turismo se presenta como campo donde convergen actores de Estado, sociedad y mercado.

Es preciso reconocer que los actores más hábiles y con mayor capital disponible aprovechan las oportunidades (económicas) del turismo y existen otros que no pueden hacerlo (Hiernaux-Nicolas, 1999), lo cual incide en las desigualdades de este campo y en la heterogeneidad que presenta, en el contexto capitalista y neoliberal.

Las acciones locales revelan vínculos con lo global, y muestran un proceso de formación del nuevo espíritu del capitalismo. Este puede ser entendido como una acumulación de ideas y acciones asociadas al capitalismo que contribuyen a justificar dicho orden y a legitimarlo (Boltanski y Chiapello, 1999), a través de determinados modos de acción, acuerdos y elecciones que son coherentes con las políticas emitidas en este marco y responden no solo a disposiciones del marco empresarial y del Estado, sino a cuestiones y mandatos de agendas globales.

Las acciones y adaptaciones pueden ser analizadas recurriendo a la Teoría de la Regulación, a través de la cual se ve la convergencia de los actores (que siguen sus intereses) en torno a acciones que corresponden al capitalismo, realizando acciones colectivas o individuales, ya sea a nivel micro como a nivel macro, las cuales requieren la toma de ciertos acuerdos (Boltanski y Thévenot, 1996).

Para la comprensión de estas dinámicas en el contexto de las políticas para el desarrollo, permite interpretar sus adaptaciones y las imbricaciones de estos debates, existen algunos aspectos básicos que conjugan conceptos de sociología a la perspectiva de economía política. Se orientan a legitimar el capitalismo, dentro de un nuevo espíritu (Boltanski y Chiapello, 1999), a través de la incorporación a esferas financieras y de mercado a las consideraciones de autonomía del Estado y de los actores. Estos tienen capacidad de acumular capital por diferentes acciones, y se relacionan por medio de la búsqueda de la seguridad y de alcanzar el desarrollo con la creación de empresas y de su participación en proyectos.

Para analizar el desarrollo, de forma amplia, se plantea el reconocimiento de la existencia de una trayectoria histórica y relaciones de poder que han legitimado sus discursos (Escobar, 1996) y han justificado las acciones de intervención en el territorio. Este es asociado a ideas y prácticas, a principios de modernidad, progreso y crecimiento, los cuales generan expectativas. Todo ello, ha incentivado la formulación de políticas asociadas a la democratización y a la lógica capitalistaoccidental en la cual destaca la racionalidad, el homo economicus (Polanyi, 1992) así como el deseo de acumulación y la negociación para la participación en diferentes actividades, dentro lógicas de mercado. Así también, la construcción de una serie de saberes técnicos, metodologías y dispositivos implementados a través de proyectos. 
El análisis se ubica en territorios dentro del llamado "Tercer Mundo" (Escobar, 1996) y en espacios rurales considerados en vías de desarrollo. La información empírica por analizar se sitúa dentro de los estudios críticos del turismo. En este campo, han predominado estudios que responden a principios económicos ortodoxos y prescriptivos (orientados a la acción), donde han proliferado manuales y documentos institucionales referidos a casos de éxito, buenas prácticas y modelos replicables en los territorios en vías de desarrollo. Es desde esta perspectiva que los proyectos y programas de intervención, dentro de los cuales se justifica la actividad turística, son evidencia de imaginarios, dispositivos, saberes técnicos y “(...) guías para una política de desarrollo (que) han sido derivadas de la experiencia histórica de los países capitalistas avanzados de Europa y Norteamérica” (Frank, 1966, p. 145).

Los estudios críticos sobre el turismo enfocan sus impactos, analizan la complejidad de intereses en juego y las diversas relaciones de poder que se establecen. Ciertos autores plantean que su realización se asocia a imaginarios globalmente difundidos y proponen que es afín a valores liberales (pos) modernos vinculados al capitalismo, al libre mercado y a los deseos de salir de la cotidianidad y entrar en contacto con "poblaciones nativas" (Mac Cannell, 1999, p. 97), catalogadas como locales y supuestamente, más auténticas.

Así, se señala la utilización de elementos religiosos, culturales, patrimoniales y correspondientes a identidades étnicas como aspectos estratégicos privatizados y mercantilizados por políticas y prácticas del Estado, por organismos que proponen estrategias económicas neoliberales para alcanzar el desarrollo a través del turismo (Hill, 2007) y por los propios pobladores locales. Por ejemplo, en la zona del Camino Inca en Cusco, los pobladores que proveen servicios de turismo establecen negocios y relaciones sociales con guías conectados a redes globales y tour operadores internacionales (Ypeij y Zoomers, 2006).

A partir de 1987, con las propuestas en torno al desarrollo sostenible (Informe Brundtland), las estrategias del capitalismo para insertar diversos aspectos de la sociedad a la lógica del mercado comienzan a intensificarse.

Esto fue deviniendo en un giro hacia el turismo alternativo donde las nuevas corrientes de turistas buscan formas afines a la sostenibilidad, tales como el ecoturismo, turismo rural comunitario (TRC), turismo místico, entre otras. En este escenario, entran en contacto con sociedades en las que se mercantiliza el patrimonio, la naturaleza, costumbres y manifestaciones culturales que, a su vez, son posibilidades para la supervivencia económica y cultural de las poblaciones locales (Hill, 2008).

Respecto al desarrollo a través del turismo, se pone en duda su capacidad para aportar equitativamente y se señala que los destinos o el establecimiento de áreas protegidas (de patrimonio cultural o natural) no contribuyen por completo a alcanzar sus beneficios o al esperado reparto de ganancias entre la población local y otros 
actores, por tanto, surgen disputas y demandas de coordinación de esfuerzos para la conformación de rutas en las que se gestione los recursos "sin invisibilizar a la población local como dueña del patrimonio...” (Ypeij y Zoomers, 2006, p. 32). Así, el turismo se convierte en escenario para el poder donde ciertas demandas no necesariamente buscan romper con el orden neoliberal, sino que reclaman una "mayor representación en las políticas culturales Andinas" o "remover obstáculos para la participación en el mercado (Hill, 2007, pp. 434-435).

Lo ocurrido en el Valle del Colca, presenta aspectos a analizar desde la "sociología de la justificación" donde es posible evaluar las acciones dentro de conceptos de pluralidad (Boltanski y Thévenot, 1996). Estos se ubican en la teoría de las convenciones donde se propone que existen lógicas que no solo son instrumentales sino que tienen que ver con el análisis de la acción colectiva que lleva a ciertos acuerdos. Los individuos tienen diferentes representaciones del mundo y están guiados por ellas, lo cual genera puntos de referencia para justificar un discurso o una acción que dé forma a un entorno y permita llegar a acuerdos. Esto responde al interés en reconocer la heterogeneidad, los conflictos y adaptaciones que se presentan entre los actores que intervienen de una actividad como el turismo.

Las acciones en torno al turismo responden a diversas lógicas que pueden mostrar principios superiores que guían las acciones. Siguiendo las propuestas de Boltanski y Chiapello (1999), podemos clasificar todo ello en diferentes tipos de "ciudades", las cuales al presentarse en una localidad, ponen en evidencia la formación de un nuevo espíritu del capitalismo.

Los autores referenciales, en sus estudios, aportan criterios para abordar transformaciones sociales vinculadas al uso de recursos locales y las acciones de las poblaciones dentro del capitalismo. Los principios superiores que se identifican en las acciones de los actores, por lo general, se acumulan y dan cuenta de justificaciones y acuerdos (Boltanski y Thévenot, 1996) que muestran la formación de un nuevo espíritu del capitalismo, asociado a progreso material; eficacia y eficiencia en la satisfacción de deseos; y modos de organización económica y social favorables a prácticas de mercado según Boltanski y Chiapello (1999).

Los actores locales se han vinculado a discursos, políticas, medidas económicas, teorías de administración, acciones de formación, dispositivos de intervención en territorios, así como saberes técnicos y evaluaciones de las elecciones o adaptaciones, lo que ha configurado un aparato de justificación afín a nociones del desarrollo. Este puede ser traducido en políticas y planes para la actividad turística en Perú, en general, y en acciones específicas en el caso de estudio. Aquí, los organismos públicos nacionales inciden en la promoción de determinado tipo de imagen, en la determinación del modelo de desarrollo a seguir y en asegurar el impulso de actividades turísticas (Hiernaux-Nicolas, 2002). 
Las justificaciones en torno a convenciones construidas socialmente son clasificadas en ciudades, responden a lógicas de acción diferentes (Boltanski y Chiapello, 1999), las cuales han sido agrupadas en ciudades que sirven como categorías de análisis que se emplean para comprender las acciones y acuerdos de quienes participan en el caso de estudio (tabla 1).

\section{Contextualización general del caso: el devenir histórico en Perú}

Para comprender las acciones que surgen en los espacios andinos, es preciso considerar las condiciones para su evolución así como las lógicas que han incidido en la formación del Estado. Estas responden a diversas etapas del capitalismo en la economía, la política y en el imaginario social.

En el Perú, desde inicios de la República, los grupos de poder se concentraron en la extracción y exportación de materias primas (guano, algodón, caña de azúcar, entre otros), de minerales y en la producción agrícola para la exportación (Bonilla, 1994). Desde entonces, se recurrió a la deuda externa para cubrir gasto público, ahondando la dependencia (inicialmente británica y posteriormente estadounidense).

El Estado peruano ha ido construyéndose en torno al discurso liberal para mediar las relaciones Estado-campesinado, perpetuando asimetrías y jerarquías similares a las de la Colonia. La oligarquía y, posteriormente, los partidos políticos y élites urbanas y regionales, impidieron transformaciones estructurales por lo que lo rural y andino se mantuvo vinculado a la herencia hacendataria colonial (Burga y Flores, 1991). En esta etapa, se sentaron bases para el primer espíritu del capitalismo (Boltanski y Chiapello, 1999), estimulando principios de la ciudad mercantil y la ciudad doméstica (alrededor del capitalismo agrario).

Posteriormente, con los procesos de urbanización de la capital (Lima) como espacio hegemónico, los actores subalternos (campesinos, artesanos y obreros) enfrentaron disparidades y conflictos de la asimilación del modelo económico capitalista liberal y occidental. El Estado fue consolidando su carácter centralista, sostenido por la convergencia entre burguesías costeñas y élites hacendatarias (Mallon, 2003). Los conflictos político-sociales desde la década del cuarenta hasta el sesenta muestran la colonialidad del poder (Quijano, 1999) así como la demanda de ciertos actores para interpelar al Estado y acumular poder, sin lograr modificar estructuras clasistas.

Las intervenciones militares (1962 a 1963 y 1968 a 1977) se relacionan con el segundo espíritu del capitalismo (Boltanski y Chiapello, 1999), pues evidencian acciones para la creación de una ciudad de mercado y la ciudad cívica (tabla 1). El reformismo militar intentó cambiar el modelo económico sin éxito, dada la crisis económica, la influencia negativa de capitales internacionales y el dominio de fuerzas del Estado oligárquico (Cotler, 2009). 
A partir de la Constitución de 1979, se inició un nuevo periodo democrático (con Belaúnde de 1980 a 1985 y García de 1985 a 1990), en el que se identificó una ciudad industrial (además de la doméstica, mercantil y cívica que fueron acumuladas de periodos previos), cuyas pruebas se relacionaron con la recesión industrial, la dinamización de exportaciones primarias, mecanismos de negociación política (con ciertos sectores) y el crecimiento del sistema financiero urbano y limeño (donde se concentró el poder). Con la transferencia de poder a los civiles, la economía y política nacionales se sometieron a las reglas del Fondo Monetario Internacional y a la aplicación de medidas de ajuste (Cotler, 2009).

Los “conflictos internos agudos y simultáneos (...) permitieron la llegada al poder a líderes antisistema" (Tanaka, 2003, p. 21) representados por el Movimiento Túpac Amaru y el grupo terrorista Sendero Luminoso. La década de los noventa marca una regresión al autoritarismo con el autogolpe y gobiernos sucesivos de Fujimori, apoyado por facciones militares. El nuevo espíritu del capitalismo comenzó a gestarse desde 1993, pues la nueva Constitución se caracterizó por su apertura a un orden político y económico neoliberal.

Con la agudización del proceso inflacionario así como la extrema pobreza y la exclusión, se modificaron las estructuras productivas (empleo, subempleo y desempleo) y las migraciones a nivel nacional e internacional (Rendón, 2012).

En los espacios rurales, con el repliegue del Estado y proliferación de proyectos de $\mathrm{ONG}$, las demandas y acciones de las comunidades andinas y de los migrantes asentados en las ciudades, se asociaron a mesas de concertación así como a proyectos vinculados a "mecanismos clientelares adoptados por organismos de ayuda estatal, autoridades, líderes políticos y organizaciones privadas...” (Landa, 2004, p. 142).

La trayectoria histórica del Estado y los problemas democráticos se vincularon a una profunda crisis económica y a procesos de descomposición social: protestas, terrorismo, narcotráfico, violencia y crisis de representación de partidos políticos tradicionales (Tanaka, 2003). Del 2000 al 2011, con el gobierno de transición de Paniagua, el de Toledo y el segundo gobierno de García, hubo un retorno a la dominación clasista, alineada a los intereses del capitalismo internacional y se continuó aplicando modelos neoliberales.

La alta vinculación a nociones de modernización y al alcance del desarrollo planteó que los espacios rurales andinos debían ser intervenidos, con lo que se puede identificar la formación del tercer espíritu del capitalismo (Boltanski y Chiapello, 1999), afín a los principios de la ciudad de los proyectos.

En este contexto, los actores locales encontraron en su adaptación al desarrollo, una manera de negociar y hacer permear sus demandas e intereses. Ciertas experiencias evidencian de activa participación local y vínculos entre municipalidades 
y comunidades (Landa, 2004), dan cuenta de la presencia del campesinado en organizaciones locales con incidencia a nivel político ${ }^{2}$.

De otro lado, dada la insatisfacción de las expectativas y demandas de transformación de los pueblos indígenas, en alineación con nociones de desarrollo capitalista y propuestas de valoración de lo étnico, el ser indígena o pertenecer a un entorno comunitario y andino se constituyó como un elemento de negociación política y acumulación de capital, así el "neoindigenismo" o el "multiculturalismo neoliberal" (De la Cadena, 2008, p. 10), fueron funcionales a la reproducción de relaciones de poder. El adaptarse al desarrollo a través de proyectos y actividades les permitió acumular capital e insertarse en las estructuras del Estado y del mercado para hacer permear sus demandas (a nivel municipal, regional, nacional e incluso, transnacional). Dentro de la perspectiva neoliberal, las políticas públicas buscaron empoderar a los beneficiarios del desarrollo, ya sea a través de capacitación, del microcrédito y del incentivo de emprendimientos para convertirlos en actores de mercado a través de la inclusión dentro del capitalismo, como receptores de ayuda y actores de crédito y consumo (De la Cadena, 2008).

Es en este marco que, luego del combate al terrorismo en la década de los noventa, se proponen políticas públicas a favor del desarrollo a través del turismo, como estrategia para la inclusión y la dinamización económica. Se iniciaron acciones de intervención en territorios rurales, los cuales presentaban recursos culturales, bienes patrimoniales (mayormente arqueológicos) y condiciones atractivas en lo natural y paisajístico. De esta forma, en respuesta a flujos de turistas y a las políticas nacionales, los actores buscan adaptarse al turismo y responder al deseo de utilizar determinados espacios como "plataformas de ganancias" (Hiernaux-Nicolas, 1999, p. 139) y como opciones para generar ingresos y hacer escuchar sus demandas.

\section{El marco de las políticas públicas en turismo en el ámbito nacional}

Como país, Perú recibió más de 3 millones de turistas extranjeros al año y presenta un porcentaje de variación anual de 11,2\% (UNWTO, 2014).

En el 2007, esta actividad aportó un 3.7\% al PBI (según estimaciones de la Cuenta Satélite en Turismo). A nivel de políticas públicas, el Ministerio de Comercio Exterior y Turismo (MINCETUR) plantea que para el 2018 se desea: "alcanzar un turismo sostenible como herramienta de desarrollo económico-social del Perú" (MINCETUR, 2008a). Las estrategias para lograrlo incluyen el fomento de la inversión, impulsar nuevos productos y destinos turísticos, aplicar modelos de gestión que promuevan la inclusión, elevar la competitividad artesanal, el acceso a mercados internacionales y el uso sostenible del patrimonio (MINCETUR, 2011). La Ley General de Turismo

2 Por ejemplo, los grupos comuneros campesinos promovieron acciones de autodefensa que contribuyeron a la lucha contra el terrorismo. 
No. 29408 señala que el turismo es una actividad de interés nacional y en el Plan Estratégico Nacional de Turismo (PENTUR) se propone el

(...) involucramiento de las poblaciones rurales (que antes no eran partícipes de los procesos de planeación y solo tomadas en cuenta ya a nivel operativo, una vez que habían incurrido en desarrollar servicios muchas veces limitados por su condición indígena o rural) para ahora tener un aporte importante a la gobernanza turística que promueve el Ministerio de Comercio Exterior y Turismo a través del PENTUR y sus postulados concordantes con el Desarrollo Turístico Sostenible y elementos que conlleva (MINCETUR, 2011, p. 3).

La creación de destinos turísticos responde a la lógica del desarrollo. A nivel nacional, la oferta de destinos se concentra en el circuito sur formado por Cusco, Puno y Arequipa, donde se encuentra el Valle del Colca.

Los logros de las políticas públicas para el turismo se miden a través de indicadores (tabla 2) para "(...) evaluar el impacto, priorizar y dar seguimiento a las directrices, objetivos y medidas que componen el PENTUR" (MINCETUR, 2008a). Los resultados al 2012 indican acciones de asistencia técnica a 20 regiones para su planificación turística, formación de 07 entes gestores de destinos (entre ellos el ente gestor Arequipa-Colca), desarrollo de planes de turismo en 10 regiones, capacitación en gestión a más de 1000 autoridades locales (Rendón, 2105, p. 701), lo que corresponde a la ciudad de los proyectos que es acumulada para propiciar la construcción de un nuevo espíritu del capitalismo.

Tabla 2. Objetivos e indicadores para evaluación de acciones en turismo

\begin{tabular}{|l|l|}
\hline \multicolumn{1}{|c|}{ Objetivos } & \multicolumn{1}{c|}{ Indicadores } \\
\hline Objetivo general & Aporte del turismo al PBI \\
\hline \multirow{5}{*}{ Objetivos específicos } & $\begin{array}{l}\text { Grado de satisfacción al turista (en porcentaje) } \\
\text { Cantidad de destinos consolidados } \\
\text { Gasto promedio de visitantes } \\
\text { Valor de inversiones en proyectos de desarrollo turístico }\end{array}$ \\
\hline \multirow{5}{*}{ Línea de acción } & Indicador \\
\hline \multirow{5}{*}{ Planificación y gestión } & PPG1. Número de entes gestores en el destino \\
\cline { 2 - 3 } & PPG2. Cantidad de medidas implementadas \\
\cline { 2 - 3 } & PPG3. Acciones implementadas sobre sus planes estratégicos y de ordenamiento turístico \\
\cline { 2 - 3 } Territorio y destino & PPG4. Número de acciones de facilitación aprobadas \\
\hline & PTD1. Cobertura de servicios básicos en los destinos turísticos \\
\cline { 2 - 3 } & PTD2. Número de señales turísticas por destino \\
\cline { 2 - 3 } & $\begin{array}{l}\text { PTD3. Denuncias policiales por asalto y robo / Número de reclamos a prestadores de } \\
\text { servicios turísticos }\end{array}$ \\
\cline { 2 - 3 } & PTD4. Vuelos comerciales a los destinos turísticos \\
\cline { 2 - 3 } & $\begin{array}{l}\text { PTD5. Grado de satisfacción de los visitantes a los aeropuertos y puertos fluviales - } \\
\text { marítimos }\end{array}$ \\
\cline { 2 - 3 } & PTD6. Instituciones educativas que incluyen al turismo en su currículo \\
\cline { 2 - 3 } & PTD7. Sanciones aplicadas a prestadores de servicios turístico \\
\hline
\end{tabular}




\begin{tabular}{|l|l|}
\hline \multirow{5}{*}{ Producto } & PP1. Número /monto de inversión de prestadores de servicios turístico \\
\cline { 2 - 2 } & PP2. Cantidad de recursos jerarquizados \\
\hline & PP3. Número/monto de inversión de prestadores en turismo especializado según PPV \\
\hline & $\begin{array}{l}\text { PP4. Número de familias beneficiadas por los emprendimientos de Turismo Rural } \\
\text { Comunitario }\end{array}$ \\
\cline { 2 - 2 } & PP5. Cuantificación, distribución y especialidad de artesanos \\
\hline \multirow{5}{*}{$\begin{array}{l}\text { Promoción, } \\
\text { comunicación y } \\
\text { comercialización }\end{array}$} & PPCC1. Número de empleados certificados en el Sector Turismo destinos con perfil detallado del visitante \\
\hline & PPCC2. Grado de cumplimiento de planes de marketing por destino \\
\hline & PPCC3. Número de acciones promocionales implementadas \\
\hline & PPCC4. Número de visitantes por destino \\
\hline & PPCC5. Número de visitantes que regresan al destino \\
\hline & comunicación y comercialización del destino \\
\hline & PPCC7. Número de visitantes que regresan al destino \\
\hline & PPCC8. Servicios en la red de información turística del destino \\
\hline & PPCC9. Número de turistas nacionales/fronterizos del destino \\
\hline PPCC10. Número de nuevos productos turísticos comercializados \\
\hline
\end{tabular}

Fuente: MINCETUR, 2008, 93-94.

Complementariamente, desde el Estado se estimula la competitividad a través del Plan Nacional de Calidad Turística (CALTUR), cuyos objetivos se orientan a la formación de recursos humanos, a la aplicación de buenas prácticas empresariales y al estímulo de la responsabilidad social y ambiental, a la mejora de la oferta turística y a la gestión sostenible, y a la creación de destinos seguros (MINCETUR, 2008b). Para ello, desde el 2009 han venido contratando consultorías especializadas, implementando programas de capacitación y publicando una serie de manuales (Rendón, 2015). Estos dispositivos y lógicas de acción responderían a la ciudad de los proyectos y evidencian un marco nacional de políticas públicas que incentivan la formación de un nuevo espíritu del capitalismo.

Dentro de los programas llevados a cabo desde el Estado (realizados por el MINCETUR, contratando servicios de consultoría externa y, en ciertos casos, con fondos de cooperación internacional), en el 2006 se creó el Programa Nacional de Turismo Rural Comunitario (PNTRC), cuyas acciones se impulsaron sobre la base de 30 años de experiencias en las que los emprendedores locales:

(...) identificaron oportunidades de negocio para atender una incipiente demanda, así como proyectos desarrollados en los últimos años con el apoyo de organizaciones de cooperación al desarrollo, empresas privadas y personas emprendedoras (MIINCETUR, 2011, p. 4). 
Los servicios consisten en brindar alojamiento en casas de familia (con servicios básicos), provisión de alimentos, muestra de costumbres y actividades familiares y productivas cotidianas y comercialización de artesanías (figura 2).

Figura 2. Pobladores locales preparándose para la venta de artesanías en el Valle del Colca (Arequipa-Perú).

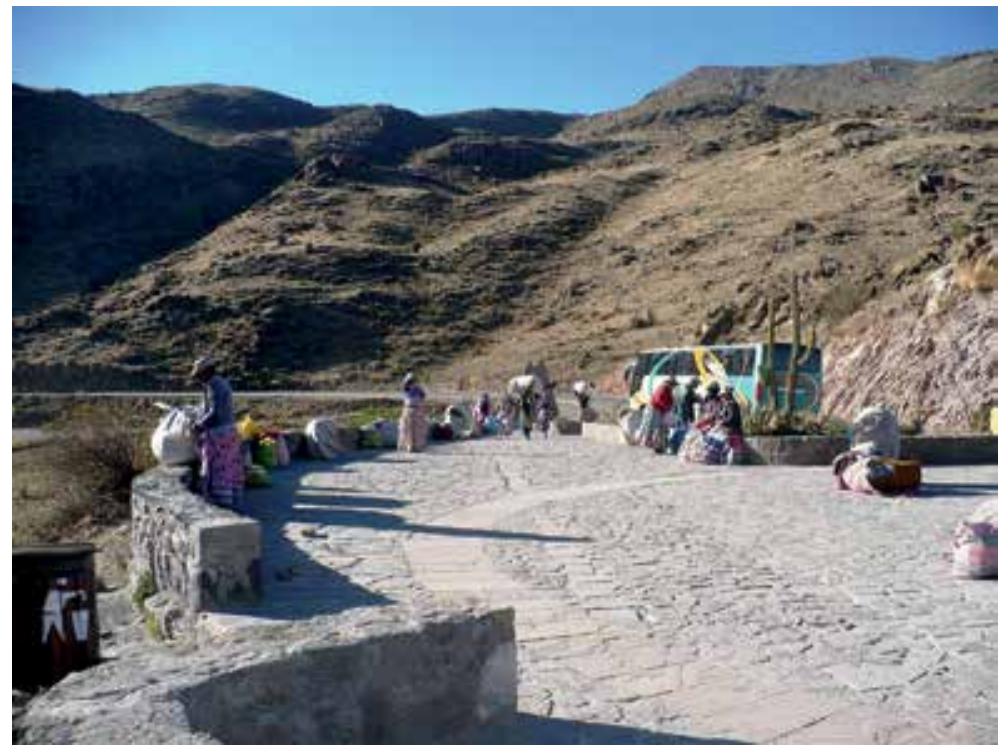

Fuente: la autora

El PNTRC plantea al turismo como una actividad beneficiosa económicamente, donde participan comunidades locales y se utilizan los recursos (culturales y naturales). Es concebido como estrategia para la inclusión de "(...) poblaciones que por años han carecido de oportunidades vinculadas al desarrollo económico, social y ambiental" (MINCETUR, 2011, p. 5). En su propuesta se señala que se ha pasado de un "enfoque de pobreza" a un "enfoque empresarial" (MINCETUR, 2011, p. 8), en el que se promueve la rentabilidad y la sostenibilidad (Rendón, 2015).

Lo expuesto prueba el acuerdo de funcionarios y autoridades del Estado así como de consultores y actores locales en torno a principios del nuevo espíritu del capitalismo. Su rasgo más visible es la justificación en torno a las intervenciones en el territorio, a la necesidad de saberes expertos y al deseo de implementar acciones medibles y de duración determinada (vinculadas a la ciudad de los proyectos). Asimismo, se asocian a la ciudad mercantil (ligada a la propiedad, riqueza, negocios y oportunidades de mercado) y a la ciudad industrial (donde priman eficacia, trabajo profesional, inversión para el progreso, medidas e indicadores), entre otros aspectos. 


\section{Actores y acciones adaptativas en torno al turismo en el Colca}

Al analizar el ámbito rural, es relevante considerar cuestiones dinámicas vinculadas a la participación, la solidaridad y la asociatividad local (Chanial y Laville, 2009), así como las acciones de competencia y colaboración, transformación de elementos culturales, recursos naturales y bienes patrimoniales. En este contexto es preciso considerar que no existe un solo principio justificador o una sola medida de éxito en dichas acciones (Rendón y Bidwell, 2015).

Las localidades del Valle del Colca presentan indicadores que denotan el por qué existe interés en adaptarse a los proyectos e incentivar el turismo. Cabanaconde tiene 2842 habitantes y Tapay 671, sus índices de desarrollo humano no superan el 0,6 y $0,5 \%$ y los ingresos familiares per cápita son aproximadamente de S/. 289.70 y S/.194.9 por mes (PNUD, 2009, p. 166), por lo que sostiene la necesidad de implementar acciones que mejoren la calidad de vida (Baldárrago, 2005).

La distribución de beneficios económicos del turismo es dispareja y poco justa (Bidwell, 2011). No obstante, algunos actores locales han buscado diversificar sus ingresos respondiendo al mercado turístico (Rendón y Bidwell, 2015).

El campo del turismo nacional es marcado por agendas globales para la cooperación, y tanto las políticas públicas nacionales como las intervenciones de ONG responden al mundo del desarrollo (Rendón, 2015), con lo cual los espacios rurales se han ido transformando. En ellos han surgido iniciativas de negociación y adaptación locales.

Los actores que han participado para generar compromisos locales y la adecuación al turismo en el Valle del Colca han realizado acciones que no solo inciden en lo local en Cabanaconde y Tapay (tabla 3), sino en el ámbito global y en los múltiples asocios a ideas e imaginarios globales en torno al turismo y a aquello que motiva los desplazamientos de los viajeros. Así también a los acuerdos y las agendas políticas para impulsar el desarrollo a través del turismo y e implementar proyectos acordes con ello, evidencian nuevos arreglos que muestran alineación a la ciudad mercantil y a la de los proyectos.

Tabla 3. Lista de actores involucrados

\begin{tabular}{|l|c|c|}
\hline \multicolumn{1}{|c|}{ Actor } & \multicolumn{2}{c|}{ Nivel (acción y relación) } \\
\cline { 2 - 3 } & Local & Global \\
\hline $\begin{array}{l}\text { Ministerio de Comercio Exterior y Turismo (MINCETUR) y Viceministerio de } \\
\text { Turismo (VMT) }\end{array}$ & $\mathrm{X}$ & $\mathrm{X}$ \\
\hline $\begin{array}{l}\text { Gobierno Regional de Arequipa - Dirección Regional de Comercio Exterior y } \\
\text { Turismo (GERCETUR) }\end{array}$ & $\mathrm{X}$ & \\
\hline Autocolca (Autoridad Autónoma del Colca y Anexos) & $\mathrm{X}$ & \\
\hline $\begin{array}{l}\text { ONG y Organismos de Cooperación Internacional: DESCO, Grupo GEA, } \\
\text { Competividad, Inovación y Desarrollo Arequipa (CID-AQP), AECID }\end{array}$ & $\mathrm{X}$ & $\mathrm{X}$ \\
\hline Organización de Gestión de Destino (OGD) & $\mathrm{X}$ & $\mathrm{X}$ \\
\hline
\end{tabular}




\begin{tabular}{|l|c|c|}
\hline Plan COPESCO & $\mathrm{X}$ & \\
\hline Programa Nacional de Turismo Rural Comunitario (PNTRC) & $\mathrm{X}$ & \\
\hline Programa Sierra Sur & $\mathrm{X}$ & \\
\hline Universidad Católica de Santa María & $\mathrm{X}$ & \\
\hline Universidad Nacional de San Agustín & $\mathrm{X}$ & \\
\hline Patronato de Turismo de Cabanaconde & $\mathrm{X}$ & \\
\hline Municipalidades distritales de Cabanaconde, Tapay y Chivay & $\mathrm{X}$ & \\
\hline Asociación de Guías Locales de Turismo Chivay, Yanque y Cabanaconde & $\mathrm{X}$ & \\
\hline Micro, pequeños y medianos empresarios locales y de Arequipa & $\mathrm{X}$ & \\
\hline Cadenas hoteleras de Arequipa y Lima & $\mathrm{X}$ & $\mathrm{X}$ \\
\hline Inversores hoteleros internacionales (principalmente franceses) & $\mathrm{X}$ & $\mathrm{X}$ \\
\hline Operadores de turismo y agencias de viaje (Arequipa, Lima y otras) & $\mathrm{X}$ & $\mathrm{X}$ \\
\hline Familias y miembros de las comunidades (Cabanaconde y Tapay) & $\mathrm{X}$ & $\mathrm{X}$ \\
\hline Turistas nacionales e internacionales & $\mathrm{X}$ & $\mathrm{X}$ \\
\hline
\end{tabular}

Fuente: Trabajo de campo y documentos institucionales.

En el Valle del Colca, el turismo se ha desarrollado informalmente y en los últimos años se ha comenzado a identificar la intervención del Estado a través de propuestas de desarrollo por medio de la promoción de acciones de planificación, capacitación y creación de emprendimientos de TRC. El lugar ha atraído inversión externa concentrada en la capital provincial (Chivay), donde llegan y se desplazan a otras zonas los visitantes, gracias al mejoramiento en los caminos que lo conectan a Arequipa gracias al Proyecto Majes $^{3}$ (Bidwell, 2011). Los poblados aledaños, entre ellos Cabanaconde y Tapay, proveen servicios de turismo establecidos por "emprendedores locales" en cuya oferta de actividades predomina el turismo de aventura, el conocimiento de "culturas vivas" y, en general, el TRC (MINCETUR, 2011). Estos emprendedores eran migrantes que retornaron a sus localidades después de acumular capital Arequipa o Lima (Bidwell, 2011), por ejemplo, o bien en el extranjero, en donde se integraban a actividades del mercado (Rendón, 2012).

La atención nacional e internacional fue captada por una expedición polaca que en 1981 navegó a lo largo del Río Colca y realizó mediciones que estimaron al Cañón del Colca como el más profundo del mundo. En 1986, el potencial turístico del área fue reconocido a través de la creación de Autocolca (tabla 3), una entidad pública autónoma encargada de regular el desarrollo turístico local); pero fue hasta después de 1992 con la captura de los líderes de Sendero Luminoso, en que los visitantes intensificaron sus desplazamientos y el turismo en el Colca inició su dinamización.

3 Concesión privada internacional que empezó en los años 60 durante el GRFA al mando del general Velasco Alvarado y culminó en los años 80 . 
Respecto a las condiciones y atractivos, adicionalmente al escenario con paisajes naturales, las aguas termales y la diversidad de manifestaciones de cultura local, el valle destaca por la presencia del cóndor andino, cuyo vuelo se aprecia desde un mirador (Cruz del Cóndor), en el camino hacia Cabanaconde (figura 3).

El tour convencional es de dos días, pero aproximadamente el 20\% de los visitantes se queda por mayor tiempo (tres días) y elije caminatas a lo largo del cañón, visitando sus pueblos o realizando actividades de turismo de aventura y TRC.

Figura 3. Turistas en el mirador de la Cruz del Cóndor, Valle del Colca (Arequipa-Perú)

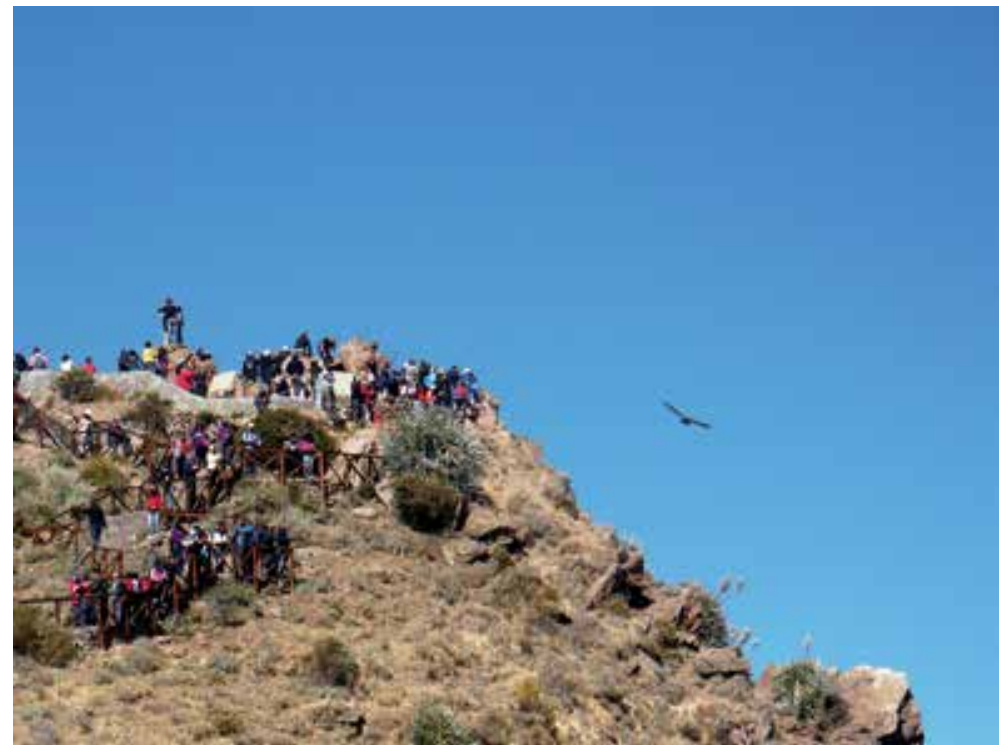

Fuente: la autora

En la actualidad, además de las acciones que lleva a cabo el PNTRC (en concordancia con las estrategias y objetivos del PENTUR y CALTUR), y algunos organismos de cooperación, existen diversos proyectos los cuales suman una inversión pública para desarrollo turístico por US\$ 6472368.10 (aprobados para el 2010). Estos responden a los lineamientos del Sistema Nacional de Inversión Pública (SNIP) y son ejecutados por MINCETUR y especialistas locales y hacen énfasis en la inversión en infraestructura ${ }^{4}$.

$4 \quad$ Según el registro de SNIP se ha invertido US\$ 850548.89 en acondicionamiento turístico de poblados; US\$ 2561492.20 en el desarrollo del corredor turístico Colca-Valle de los Volcanes-Cotahuasi; US\$1 209818.50 en el mejoramiento de la plaza de armas de Chivay; US\$ 1850508.50 en mejoramiento de la carretera Yanque Achoma. 
Autocolca ha venido registrando el número de turistas desde 1998, cuando se comenzó a cobrar un valor por la entrada al valle (actualmente bajo la forma de boleto turístico). Dicha institución indicó que en el 2011, la zona recibió 175030 visitantes (captando un $17 \%$ de los visitantes a Perú), de los cuales 55435 fueron nacionales y 119605 internacionales ${ }^{5}$. Sin embargo, las cifras y las evidencias locales del aporte de la actividad turística son ambivalentes y se contradicen: Autocolca presenta información discordante con la que provee el Gobierno regional de Arequipa a través de la DIRCETUR y por el MINCETUR. Se denuncia, de un lado, problemas asociados a la llegada e instalación de cadenas hoteleras con capitales de Lima o del extranjero, inversores de otros centros urbanos interesados en el turismo, elevación en el precio de los terrenos, así como demandas asociadas a negociaciones para el acceso al agua en la zona.

A pesar de estas disputas, la población y sus autoridades locales coinciden en demandar mayor apoyo de las ONG e instituciones del Estado para que inviertan en el desarrollo turístico y la atracción de visitantes a la zona, lo que muestra "la existencia de múltiples lógicas sobre el fomento y propósito del turismo como impedimento para la organización y la cooperación (...) y múltiples discursos y rumores" (Lyall, 2011, p. 95) que crean duplicidad en las acciones, bien confusión y conflictos en entre los actores locales. Unos a favor y otros en contra del turismo.

La lógica capitalista está inspirada por los éxitos comerciales, en la obtención de rentabilidad individual y las relaciones de mercado. Sin embargo, existen otras acciones que deberían ser reconocidas a nivel local: la participación en asuntos públicos los actos de consumo (Hirschman, 2002). Esta diversidad se da entre actores con intereses que hacen que tomen decisiones para llegar a acuerdos en determinadas condiciones de precios de mercado, ingresos, relaciones de poder y de preferencias de ocio que no solo tienen que ver con motivaciones económicas sino de estima, autonomía, discusiones entre ser y tener, entre otros aspectos.

Mientras el desarrollo de infraestructura ha sido reconocido, incluso empleado como negociación estratégica y elemento de reconocimiento político (Cameron, 2009) por el cual muchos gobiernos locales han volcado su atención al turismo. Existen tensiones relacionadas con el desorden, falta de regulación y acuerdos entre operadores de turismo, disputas en torno a los precios y excesiva competencia en torno al desarrollo turístico (Baldárrago, 2005) debido a una creciente dominación de actores urbanos (de Lima y Arequipa), quienes ignoran a actores de localidades periféricas y concentran sus actividades en Chivay o el mirador, además de influencias culturales adversas y contaminación ambiental.

Las acciones en Cabanaconde y Tapar, distritos geográficamente periféricos en el Valle del Colca, son interesantes en tanto muestran cómo las acciones de actores

5 Respecto a la renta y los beneficios económicos obtenidos de la actividad turística, no existen datos ministeriales oficiales para los distritos de Cabanaconde y Tapay. 
responden a diversas lógicas de acción y son guiadas por principios que podrían corresponder a la formación de un nuevo espíritu del capitalismo, en concordancia con las propuestas de los autores analizados, en este caso, en torno al turismo.

Cabanaconde es el centro urbano más grande del valle inferior (con una población estimada en 3000 habitantes aproximadamente), y tiene el segundo más alto nivel de salario promedio del Valle (después de Chivay); la población de Tapay es de 700 personas y se ubica de forma dispersa en pequeños establecimientos a lo largo del Cañón. Este es el distrito más aislado y con menor nivel de ingresos del Valle (el área ha sido recientemente electrificada y es carente de infraestructura sanitaria).

Los migrantes han mantenido vínculos con sus familias y comunidades originarias, principalmente a través del envío de remesas que han influido en las respuestas al turismo (Gelles, 2000; Paerregaard, 1997), lo que permite identificar principios que corresponden a la ciudad del renombre y la ciudad doméstica (Tabla 1).

Las comunidades locales, a través de las acciones de los micro y pequeños empresarios, mostraron acciones espontáneas ante la actividad turística y, con la finalidad de obtener beneficios económicos, innovaron y recurrieron a múltiples recursos para aprovechar la llegada de visitantes atraídos a la zona, lo cual es prueba de una adaptación a las condiciones y relaciones de mercado, que podría corresponder a una ciudad mercantil así como una acumulación de principios en torno a la ciudad doméstica y de la inspiración (tabla 1).

Los alojamientos y servicios de restaurante son manejados por familias locales (mayoritariamente). Muchos de ellos comenzaron a finales de 1980, cuando los primeros turistas internacionales llegaron para visitar el cañón. Otros comenzaron ofreciendo espacios para camping $\mathrm{y}$, gradualmente, implementando hostales $\mathrm{y}$ piscinas (para aprovechar las aguas termales), con apoyo de ONG y de gobiernos locales. En el 2010 se identificaron más de 20 proveedores de hospedaje en los dos distritos, los que son de diverso tipo, desde cabañas locales hoteles de tres estrellas (Bidwell, 2011).

Los emprendedores que participan en el turismo no corresponden a las históricamente privilegiadas y hegemónicas élites locales sino que, debido a las migraciones y al turismo, tienen una base local (Rendón, 2012). Muchos migrantes tienen nuevas capacidades las cuales aplican al retornar y su capital económico ha incidido en diversificar sus actividades familiares y productivas vinculándose a redes de comercio o a la provisión de servicios de turismo (Rendón y Bidwell, 2015). Esto ha contribuido en su acceso a nuevas posibilidades de educación, a la obtención de recursos económicos y a una mayor capacidad de negociación.

Las voces locales y las acciones de adaptación al turismo se pusieron en evidencia durante la realización de un taller de capacitación realizado en el Valle del Colca durante el 2012, en el marco de las actividades de un proyecto impulsado por el Programa Regional Sur de la ONG Centro de Estudios y Promoción del Desarrollo 
(DESCO Sur). Los asistentes, hombres, mujeres y algunos niños de Cabanaconde y zonas aledañas manifestaron su interés en organizar actividades de turismo rural. Para su impulso requerían mayor asesoría técnica para la operación turística, financiamiento y apoyo en el acceso al mercado. Este proyecto implementó dos alojamientos rurales, intentó montar un museo local, entre otras iniciativas.

Durante el taller, plantearon la reconstitución de las asociaciones de arrieros (que abarcaría a 60 personas) que podrían participar en ofrecer servicios para el transporte con mulas y caballos que servían en el recorrido en el Cañón del Colca.

Pese a todo ello, no se han producido mayores cambios en la participación directa de campesinos locales, los cuales se conforman y adaptan a la afluencia de turistas (gestionada desde Arequipa, por operadores de otros centros urbanos o con llegadas de turistas independientes que emplean guías de viaje) y a la oferta actual: participan a través de la venta de bebidas, alimentos y algunos ofrecen alojamiento (de forma esporádica) y otros, por lo general mujeres, comercializan artesanías.

Otros residentes de Cabanaconde, obtuvieron beneficios económicos actuando como guías de turismo, vendiendo artesanía, comida y bebida en el mirador (Cruz del Cóndor). La guianza turística fue realizada informalmente y, luego, en el $2000 \mathrm{y}$ 2001 se dieron iniciativas para la profesionalización, por lo que aproximadamente 40 residentes recibieron cursos de capacitación financiados por la Universidad Católica de Santa María (Arequipa), Autocolca y la Agencia Española de Cooperación Internacional para el Desarrollo (AECID), que invirtió en la restauración de iglesias coloniales (figura 4).

Figura 4. Iglesia construida en sillar y piedra (Cabanaconde, Arequipa-Perú)

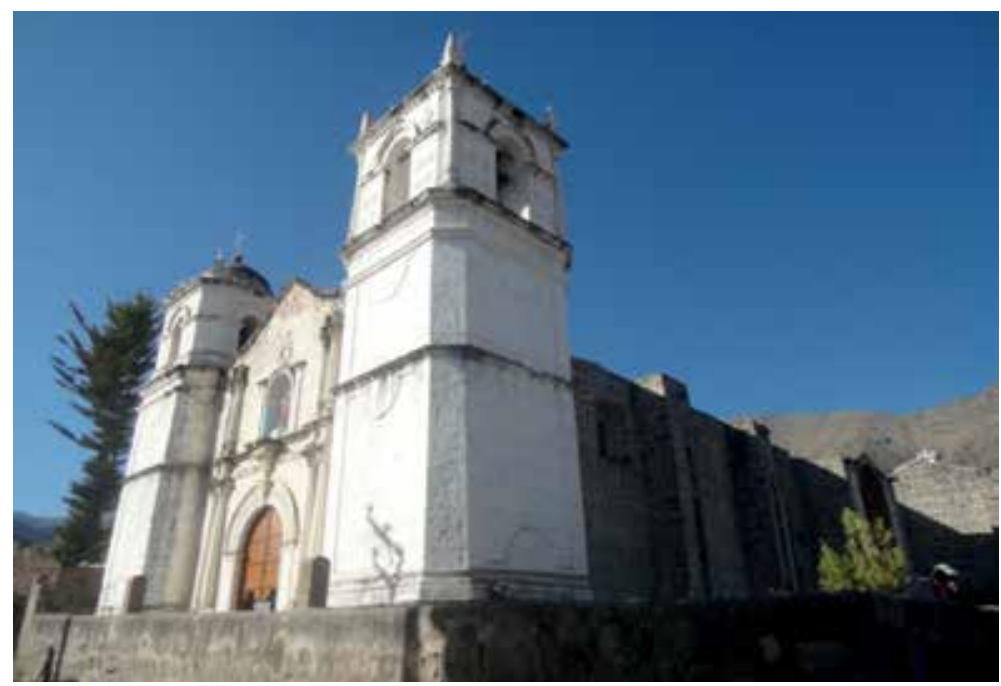

Fuente:la autora 
Se ha identificado que un grupo de mujeres se desplaza a la Cruz del Cóndor para aprovechar la popularidad de dicho lugar como destino turístico y beneficiarse con la venta de comida, bebidas y artesanías (Baldárraga, 2005 y Bidwell, 2011), mostrando una lógica de acción y adaptación al mercado, pero también en torno a la solidaridad (Chanial y Laville, 2009). Para aquellos capaces de mantenerse en el mercado del turismo, los ingresos por el comercio contribuyen a diversificar sus ganancias (que tradicionalmente provienen la producción agrícola).

Algunos residentes han diversificado sus ingresos y mejorado sus condiciones de vida, otros han intentado obtener beneficios esporádicos vendiendo productos o servicios ocasionales (figura 5). Esto ha sido producto de su esfuerzo y sin contar con asistencia técnica externa (las acciones de cooperación y proyectos del sector público se concentran en otras zonas del Valle, por ejemplo Chivay y Sibayo).

Figura 5. Campesina con auquénido ofrece que le tomen fotos (Cabanaconde, Arequipa-Perú)

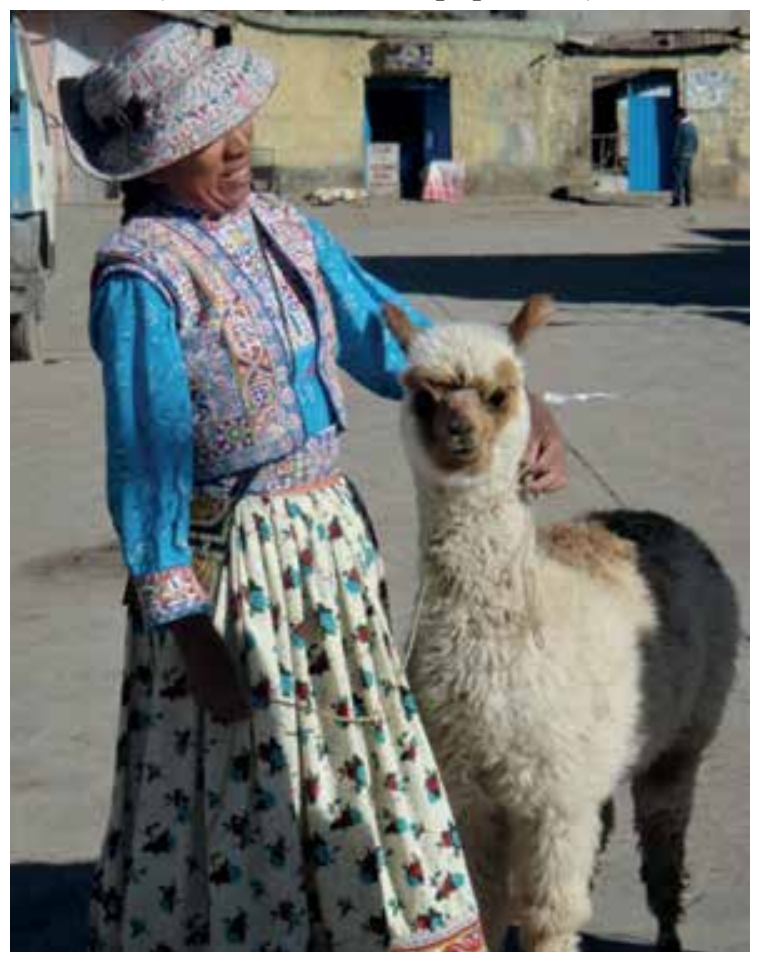

Fuente:la autora

La intervención foránea no es determinante para alcanzar beneficios o el éxito en torno al turismo (Rendón y Bidwell, 2015). El interés local y los emprendimientos evidencian motivaciones de diverso tipo: deseo de aprendizaje, capacidad de 
adaptación, estrategias de supervivencia, flexibilidad, observación e intercambio (de ideas, experiencias y acciones), creatividad e innovación, solidaridad e iniciativas de asociatividad (Chanial y Laville, 2009) y la búsqueda de alternativas económicas acompañadas por lazos familiares, territoriales y de colaboración de diversa índole.

Los pobladores locales y los guías de turismo insisten en que los turistas pasen por la zona de "apachitas", donde se elevan pedidos y deseos de visitantes y transeúntes ${ }^{6}$, y se observa las llamas, vicuñas y ovejas de la zona (figura 6). Proponen actividades en el cañón que incluyen turismo de aventura, observación del vuelo de cóndores y el intercambio con pobladores locales a través de danzas, gastronomía o de sus actividades productivas y quehaceres cotidianos. Esto aporta conocimiento del entorno local, sentido místico al encuentro de turismo y muestra intentos por intercambiar saberes, formas de vida y creencias, más allá de elementos monetarios.

Figura 6. Apachitas (Valle del Colca, Arequipa-Perú)

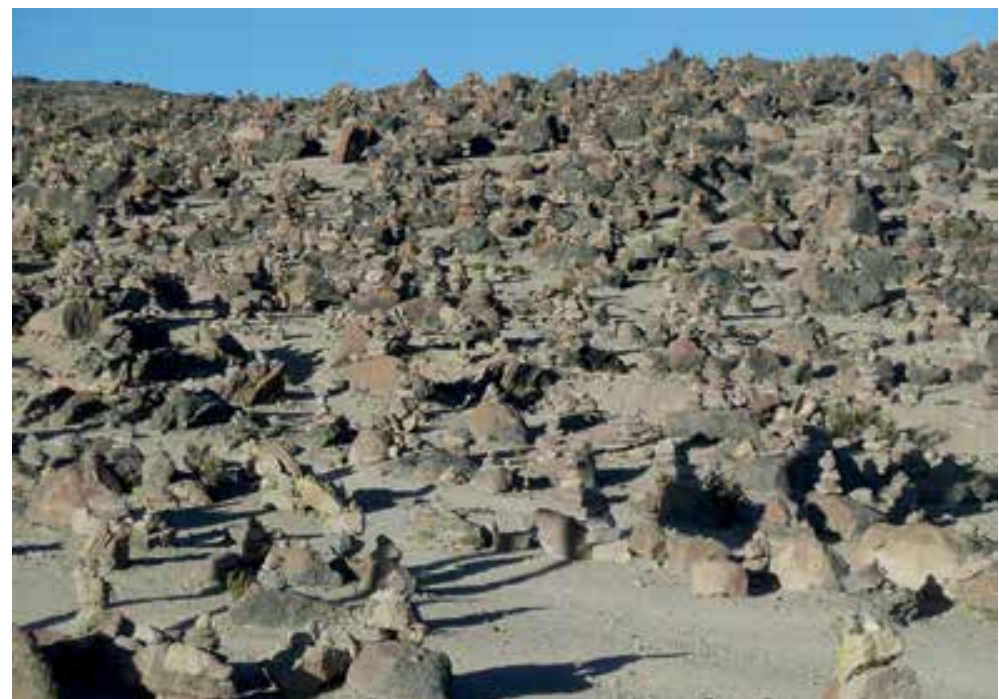

Fuente:la autora

Dentro del Valle del Colca, un lugar emblemático donde ha existido organización local (con participación comunitaria y de sus autoridades) es Sibayo. En dicha localidad se han tomado medidas para el mantenimiento de técnicas de construcción de casas andinas tradicionales (llamadas "casas vivenciales") y han pasado por diversas experiencias de capacitación dentro del PNTRC e intercambio con programas de desarrollo de ONG. En la actualidad, a pesar de contar con documentos

6 En los recorridos se hace participar a los visitantes a través de prácticas de creencias andinas locales, por ejemplo, el apilar piedras que toman forma de "apachita", donde los visitantes pueden formular deseos, lo cual aporta materialidad y misticismo a la experiencia durante su viaje. 
de planificación, acuerdos y vínculos con entidades externas, dicha zona comparte problemáticas de desarrollo con Cabanaconde y Tapay.

Esto permite reflexionar respecto a la justificación para asistir técnicamente a las poblaciones rurales e incluirlas en estrategias pre-establecidas y planes de desarrollo (como el PENTUR o el CALTUR), formulados desde arriba hacia abajo. La trayectoria en el Colca muestra diversas lógicas de desarrollo y el surgimiento de iniciativas demandadas o ejecutadas localmente. Los pobladores tienen interés en adaptarse al mercado como forma de supervivencia, para diversificar sus economías y como negociación política. En ello, denotan estrecha relación con la ciudad de los proyectos, según propuestas de Boltanski y Chiapello (1999) una de las más visibles para la configuración del nuevo espíritu del capitalismo.

\section{Conclusiones}

Es preciso considerar el devenir histórico de una nación para comprender su configuración social, sus transformaciones políticas y el devenir económico en determinado territorio. Los procesos históricos muestran las diferentes etapas asociadas a la formulación de políticas y a las dinámicas locales que se pueden conocer a través de la acción de los actores, cuyas lógicas responden a principios que permiten identificar la formación del nuevo espíritu del capitalismo, siguiendo las propuestas teórico-conceptuales de Boltanski, Chiapello y Thévenot.

La creación de programas y proyectos en torno al turismo como estrategias de desarrollo y como respuesta mercantil al uso de los recursos y a la incorporación de demandas y aspiraciones locales para la inclusión y la mejora en la calidad de vida, evidencian un marco nacional de políticas públicas que incentivan la formación de un nuevo espíritu del capitalismo.

El turismo del Valle del Colca es un escenario propicio para aplicar los conceptos propuestos por Boltanski, Chiapello y Thévenot, y abordar la complejidad de las acciones locales, las cuales no solo se guían por principios económicos sino que se vinculan a cuestiones políticas y sociales. Su aporte al reconocimiento de decisiones de los actores y de estos en su adaptación al desarrollo, permite transcender las limitaciones teóricas descontextualizadas de la elección racional y los supuestos de la economía clásica vinculados al capitalismo, para mirar de forma dinámica lo local.

El caso de estudio muestra la existencia de diversas lógicas y permite evidenciar la heterogeneidad de actores y sus adaptaciones en torno al nuevo espíritu del capitalismo. Son guiados por sus intereses, por principios superiores y por necesidades que disputan en el marco de relaciones comunitarias, cuestiones organizativas locales y un marco político amplio. Los actores locales en el Valle del Colca actúan para adaptarse al mercado, diversificar sus economías a través 
del turismo y mantienen vínculos con redes migratorias, ONG e instituciones de Gobierno, dentro de cuestiones vinculadas al desarrollo.

La información analizada muestra procesos de negociación local conectados a lo global. Se evidencia claramente la acción para el desarrollo asociada a iniciativas de TRC que se intenta impulsar desde el estado peruano, las ONG (nacionales e internacionales) y actores locales emprendedores. En este Valle se evidencian iniciativas de organización local, adaptación al mercado, solidaridadad y aprovechamiento de oportunidades que puede presentar el turismo.

Las prácticas locales han dado cuenta de la existencia de lógicas plurales, algunas de ellas correspondientes a la formación del nuevo espíritu del capitalismo, sin embargo, muestran otras que no necesariamente responden a ello, sino que se relacionan con prácticas andinas de organización y vinculación social, redes familiares, colaboración y adaptación a prácticas de mercado y vinculación a complejos procesos migratorios. Todas ellas, no necesariamente responden a motivaciones o principios económicos o nociones de desarrollo occidentales.

La evolución del espíritu del capitalismo, que enfatiza la acumulación ilimitada y centra los circuitos económicos en el objetivo de obtener beneficios, lleva a considerar que los objetos tienen un valor de uso y que las acciones se vinculan a la búsqueda de rentabilidad que corresponden a las críticas formuladas por Polanyi, Frank, Escobar y otros diversos autores.

Los criterios propuestos, por un lado, implican el interés de alcanzar el desarrollo, y por otro, dependencia así como un posicionamiento débil dentro de un contexto nacional y global de relaciones de poder, responden a nociones vinculadas al crecimiento, al progreso y a la eficacia, y a nociones subjetivas vinculadas al nuevo espíritu del capitalismo. Sin embargo, es preciso reconocer que este marco de análisis (y su marco justificativo) es planteado desde una perspectiva occidental, la cual podría dejar de lado ciertos principios y motivaciones para la acción de las comunidades rurales de los Andes, por ello, se requeriría plantear modificaciones que permitan trascender estas limitaciones.

Este análisis presume la existencia de pruebas de la diversidad de lógicas de acción de los actores que participan en el turismo. Desde la lógica de intervención, planificación, asistencia técnica y el aparato burocrático-institucional que se forma sobre la base de normativas, planes, objetivos, estrategias y acciones del MINCETUR (Ley General de Turismo, PLANDETUR, CALTUR, PNTRC, entre otros), se identifica relación con discursos y prácticas para alcanzar el desarrollo y correspondencia con la acumulación de ciudades del nuevo espíritu del capitalismo.

La información sobre las acciones de los pobladores de las localidades analizadas en el Valle del Colca pone en evidencia diversas adaptaciones y negociaciones que tienen que ver con la pluralidad de lógicas de acción de los actores locales, dentro de un contexto de relaciones de poder. Estas no evidencian intenciones de ruptura con 
los marcos de acción política o separación de las estrategias del Estado ni rechazo a prácticas capitalistas, sino más bien, acciones para adaptarse y negociar de mejor forma en el mercado, en este caso, incorporando al turismo en sus actividades de subsistencia y producción.

Existe la necesidad de realizar un estudio exhaustivo y detallado, en el que se apliquen técnicas etnográficas de investigación de campo para obtener información in situ y recoger las opiniones de los actores locales que permitan profundizar en la realidad local, conocer sus intereses y analizar las lógicas que motivan sus acciones con mayor profundidad. Todo ello podría contribuir en identificar elementos que sustenten argumentos para la diversidad y las justificaciones de la formación del nuevo espíritu del capitalismo que, como hemos visto, provee elementos para el análisis que aún deben ser profundizados con el objetivo de comprender la realidad andina. Esto pone en evidencia las diferentes acciones de adaptaciones entre los actores, los cuales se vinculan a través de políticas, imaginarios, proyectos, empresas y sus acciones en sí mismas con lo local y lo global y, al mismo tiempo, permite introducir perspectivas que muestran la complejidad de este campo así como la necesidad de abrir espacios para dar visibilidad a las iniciativas para negociar, demandar participar en los proyectos y los deseos de tomar parte en el mercado.

\section{Referencias}

Baldárrago, E. (2005). Turismo y desarrollo económico local: El caso del Cañón del Colca en la Provincia de Caylloma - Arequipa. Consorcio de Investigación Económica y Social (CIES) y Universidad Nacional de San Agustín (UNSA). Accesado 02-05-2014. Recuperado de http:/cies.org.pe/es/investigaciones/ analisis-sectorial/turismo-y-desarrollo-economico-local-el-caso-del-canon-delcolca

Bidwell, S. (2011). The Development Impact of Rural Tourism in Peru's Colca Valley: Linking Grassroots and Structuralist. Perspectives. DEVE 592, Wellington: Victoria University of Wellington.

Boltanski, L., y Chiapello, E. (1999). Le nouvel esprit du capitalisme. Paris: Éditions Gallimard.

Boltanski, L., y Thévenot, L. [1996 (1991)] On Justification, Economies of Worth. Pinceton University Press.

Bonilla, H. (1994). Guano y burguesía en el Perú (3 $3^{\mathrm{a}}$ ed.), Quito: FLACSO-Ecuador.

Burga, M., y Flores Galindo, A. (1991). Apogeo y crisis de la república aristocrática. Oligarquía, aprismo y comunismo en el Perú, 1895-1932 (5 ed.) Lima: Rikchay Perú. 
Cameron, J. (2009). Development is a bag of cement': the infrapolitics of participatory budgets in the Andes. Development in Practice, 19(6), 692-701.

Chanial, P., y Laville, J. (2009). Asociatividad. En Cattani, A., Coraggio, J., y Laville, J. Diccionario de la otra economía: lecturas sobre economía social $\left(1^{\mathrm{a}} \mathrm{ed}\right.$., pp. 36-42). Buenos Aires: Altamira.

Cotler, J. (2009[1978]). Clases, Estado y Nación en el Perú. (3ªd.). Lima: IEP.

De la Cadena, M. (Ed.). (2008). Formaciones de Indianidad. Articulaciones raciales, mestizaje y nación en América Latina. Bogotá, Lima, Quito: Envión.

El Comercio (2015). Más de 200 mil turistas visitarán el Valle del Colca este año. 11-10-2015, http://elcomercio.pe/peru/arequipa/mas-200-mil-turistas-visitaranvalle-colca-este-ano-noticia-1847461. Recuperado el 23 de noviembre de 2015.

Escobar, A. (1996). La invención del Tercer Mundo. Construcción y deconstrucción del desarrollo. Bogotá: Grupo Editorial Norma.

Espinosa, B. (2010). Agir dans une plurité de mondes: le cas du commerce équitable en Équateur. Université Catholique de Louvain: Presses Universitaires de Louvain.

Gascón, J. (2005). Gringos como en sueños: Diferenciación y conflicto campesinos en los Andes peruanos ante el desarrollo del turismo. Lima: IEP.

Gelles, P. (2000). Water and Power in Highland Peru: the Cultural Politics of Irrigation and Development. New Brunswick, Londres: Rutgers University Press.

Gunder, F. (2005 [1966]). El desarrollo del subdesarrollo. En El nuevo rostro del capitalismo. Monthly Review Selecciones en Castellano, No 4, 144-157.

Hiernaux-Nicolas, D. (2002). ¿Cómo definir el turismo? Un repaso disciplinario. Aportes y Transferencias, 6(2), 11-27.

Hiernaux-Nicolas, D. (1999). Cancun Bliss. En Judd, D. y Fainstein, S. (Eds.). The Tourist City (pp. 124-139). New Haven, Londres: Yale University Press.

Hill, M. D. (2008). Inca of the Blood, Inca of the Soul: Embodiment, Emotion and Racialization in the Peruvian Mystical Tourist Industry. Journal of the American Academy of Religion, 76(2), 251-279.

Hill, M. D. (2007). Contesting Patrimony: Cusco's Mystical Tourist Industry and the Politics of Incanismo. Journals Ethnos, 72(4), 433-460.

Hirschman, A. (2002). Introduction: A Private-Public Cycle? y On Disappointment. En Shifting Involvements: Private Interest and Public Action (pp. 3-24). Princeton University Press.

Kervin, B. (1987). La economía campesina en el Perú: Teorías y políticas. SEPIA II. Recuperado el 23 de abril de 2013 de http://www.sepia.org.pe. 
Landa, L. (2004). Waqamuwanku haykumuyku (nos llaman, y entramos), Los modos de participación en el espacio rural: Cusco y Apurímac. Serie Estudios de la Sociedad Rural, 27. Lima: IEP.

Lyall, A. (2011). Estado y turismo comunitario en la sierra central. En Prieto, Mercedes (coord.). Espacios en disputa: el turismo en Ecuador (pp. 66-98). Quito: FLACSO Sede Ecuador.

Mac Cannell, D. [1999 (1976)]. The Tourist: A New Theory of the Leisure Class. New York: Schocken Books.

Mallon, F. (2003). Campesino y nación: la construcción de México y Perú poscoloniales. México: CIESAS, Colegio de Michoacán, Colegio San Luis de Potosí.

MINCETUR. (2011). Productos de turismo rural comunitario en los destinos turísticos del Perú. Lima: SOLVIMA GRAF.

MINCETUR. (2008a). PENTUR - Plan Estratégico Nacional de Turismo 20082018. Sintesis para la puesta en operación. Lima: GMC Digital.

MINCETUR. (2008b). CALTUR - Plan Nacional de Calidad Turística del Perú. Lima: Artprint.

Monge, C. (1994). Transformaciones en la sociedad rural. SEPIA $V$. Recuperado el 12 de enero de 2014 de http://www.sepia.org.pe

Paerregaard, K. (1997). Linking Separate Worlds: Urban Migrants and Rural Lives in Peru. Explorations in Antropology Series. Oxford, New York: Berg.

PNUD. (2009). Informe de desarrollo humano Perú, aproximación al índice de desarrollo humano. Recuperado el 14 de mayo de 2014 de http://www.undp.org/ content/dam/peru/docs/Publicaciones\%20pobreza/Desarrollo\%20Humano\%20 2009/parte2-anexos.pdf

Polanyi, K. (1992). La gran transformación. Los orígenes políticos y económicos de nuestro tiempo. Fondo de Cultura Económica: México.

Prieto, M. (coord.) (2011). Espacios en disputa: el turismo en Ecuador. Quito: FLACSO Sede Ecuador.

Rendón, M. L. (2012). Sujetos diversos, mundos plurales: Análisis de los modos de acción y el nuevo espíritu del capitalismo en torno al turismo en el Valle del Colca (Arequipa, Perú). Mesa 8, Jornadas de Estudios Andinos: Pensando la multiplicidad y la unidad en los Andes. Tilcara: CLACSO, Facultad de Filosofía y Letras de la Universidad de Buenos Aires, FLACSO Ecuador. (Documento no publicado). 
Rendón, M. L. (2015). La agenda para el desarrollo a través del turismo en Perú y su relación con intereses internacionales. Revista PASOS - Turismo y Patrimonio Cultural, 13(3), 697-708.

Rendón, M. L. y Bidwell, S. (2015). Success in progress? Tourism as a tool for inclusive development in Peru's Colca Valley (pp. 201-233). En Panosso, A. y Trigo, L. (eds.). Tourism in Latin America, Cases of success. Suiza: Ed. Springer.

Tanaka, M. (2003). La situación de la democracia en Bolivia, Chile y Ecuador a inicios de siglo. Serie Democracia, 7, 15-31. Lima: Comisión Andina de Juristas.

Ypeij, A., y Zoomers, A. (editoras). (2006). La Ruta Andina. Turismo y desarrollo sostenible en Perú y Bolivia. Quito: Ediciones Abya Yala - IEP - CBC - CEDLA.

UNWTO. 2014. Panorama OMT del Turismo Internacional. Madrid: Organización Mundial del Turismo. 